\title{
GATE CONTROL THEORY OF PAIN
}

\section{Mrs. Baby Uma* I Dr. Ian Clement**}

* Research Scholar, Himalayan University, Itanagar, Arunachal Pradesh, India

** Professor cum Vice-principal, Bhai Gurdas Institute of Nursing, Sangrur, Punjab, India DOI: http://doi.org/10.47211/idcij.2020.v07i03.014

Received $10^{\text {th }}$ June 2020, Accepted $27^{\text {th }}$ June 2020, Available online $10^{\text {th }}$ July 2020.

\section{ABSTRACT}

Gate control theory was described by Melzack and Patric Wall in the year 1965. This theory explains about a pain modulating system. Every part of the human body has its own nerve supply. Those nerves carry the electrical impulses generated in response to various sensations like touch or any painful stimuli which are transmitted to the brain and the spinal cord. The gate control theory of pain states that the spinal cord contains a neurological gate that allows or blocks certain stimuli to pass on to the brain.

Key words: Gate control theory, pain modulating system, nerve supply.

\section{ABOUT AUTHORS}

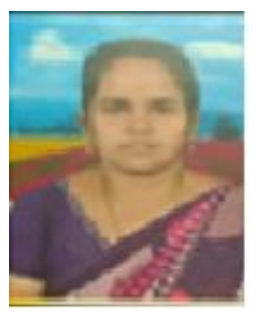

Author Mrs. Baby Uma, K. is a PhD scholar at the Himalayan University at Itanagar in the Indian state of Arunachal Pradesh. She has attended various national and international conferences and workshops.

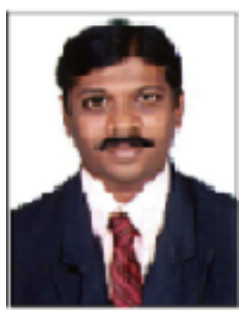

Author Dr. Ian Clement is Professor cum Vice-principal of Bhai Gurdas Institute of Nursing at Sangrur in Punjab, India. He has presented papers in various conferences and seminars. He has many research publications to his Name 


\section{ARTICLES}

\section{INTRODUCTION}

Pain is an unpleasant subjective experience. Peripheral nerve fibres are involved in transmission of sensory signals. The nerve fibres can be classified into three types - A, B and C fibres. A -fibres (Sub types are - Aalpha, A- beta, A-gamma, A- delta). A- Alpha fibres are the largest, and the A-delta fibres are the smallest. The A- fibres carry the sensations like touch, pressure to the spinal cord. The A-delta fibres are faster and carry the sharp pain signals while C- fibres carry diffused pain signals to the spinal cord.

\section{THE NOCICEPTIVE SIGNALS PATHWAYS FROM THE PERIPHERY TO THE BRAIN}

1. The primary neurons (from the nociceptors to the dorsal horn of the spinal cord),

2. Secondary neurons (from the dorsal horn to the thalamus), and

3. Tertiary neurons (from the thalamus to the cortex).

\section{REGULATORS OF PAIN}

Chemical substances that modulate the transmission of pain are released into the extracellular tissue when damages occur. They activate the pain receptors by irritating nerve endings. Pain signals can cause A-delta and $C$ fibres to release an excitatory neurotransmitter such as Glutamate, adenosine tri-phosphate, calcitonin gene-related peptide (CGRP), bradykinin, nitric oxide and Substance-P (blocking pain transmission) and stimulate second order neurons. Pain signals also can cause A- beta and C-fibres to release inhibitory neurotransmitters like Gamma-amino butyric acid (GABA) and Encephalin or Enkephalin, endorphins, serotonin, norepinephrine, acetylcholine (ACh), which inhibit an interneuron, thereby opening the gate for transmitting pain signals to second order neuron. Tactile stimulation like massaging, stroking an affected area closes the gate and raises the pain threshold.

\section{FACTORS WHICH INFLUENCE OPENING AND CLOSING THE GATE}

Factors involved in opening or closing the gate are: -

- The amount of activity in the pain fibres

- The amount of activity in other peripheral nerve fibres

- The messages that descends from the brain.

Gate may be closed by: Relaxation, meditation, short term use of pain medication, aerobic exercise, massage, decreasing depression, stress management, taking control of your life, increasing positive and meaningful behaviours, distraction from the pain, acceptance, doing Work, watching TV and reading book.

Gate may be opened by: Physical factors like Bodily injury, emotional disturbances like anxiety, depression, expectations and belief about pain, previous experience and behavioural factors like concentrating on painful stimuli. 


\section{ARTICLES}

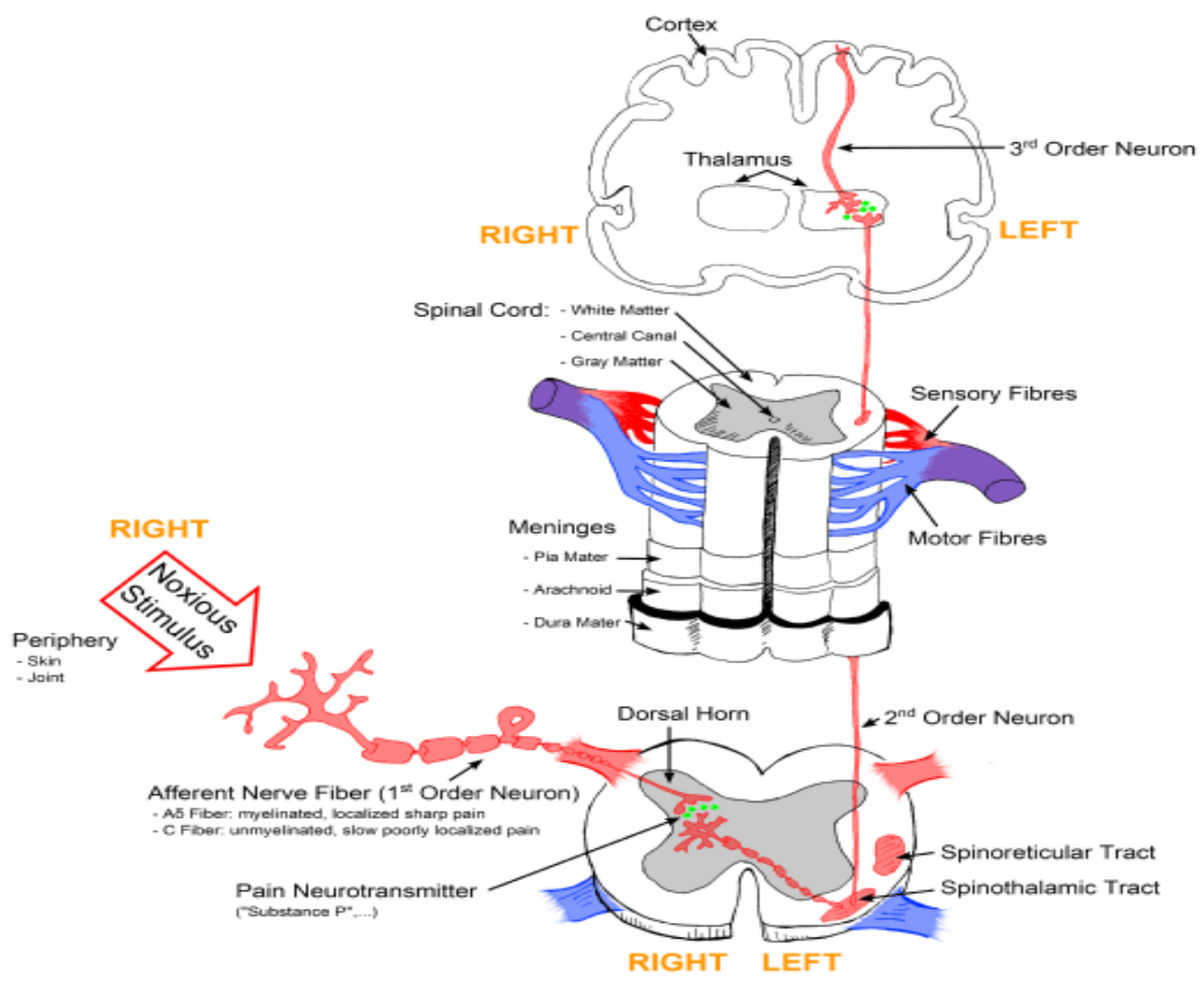

\section{Gate control mechanism:}

* Pain receptors or nociceptors (found throughout all tissues except the brain) are free nerve endings that respond to painful stimuli, and they transmit information to the brain. They are stimulated by biological, environmental, and psychological factors.

* Pain perception occurs when these stimuli are transmitted to the spinal cord and then to the central areas of the brain. Pain impulses travel to the dorsal horn of the spine where by synapse with dorsal horn neurons in the substantia gelatinosa and then ascend to the brain.

* The basic sensation of pain occurs at the thalamus. It continuous to the limbic system (emotional centre) and the cerebral cortex, where pain is perceived and interpreted.

* Two types of fibres are involved in pain transmission. The Large A-delta fibres produce sharp pain, called fast pain or first pain, typically stimulated by cut, an electrical shock, or a physical blow.

* Transmission through the A fibres is so fast that the body's reflexes can actually respond faster than the pain stimulus, resulting in retraction of the affected body part even before the person perceives the pain. After this first pain, the smaller C fibres (small and have lack of myelin sheath) transmit pain more slowly than the A fibres.

* Large fibre activity however excites the inhibitory neurons which diminishes the transmission of pain information. When there is more large fibre activity in comparison to pain fibre activity people tend to experience less pain (gates are closed).

* Pain fibres impede (delay or prevent) the inhibitory neurons, allowing pain information to travel up to the brain. When there is more small fibre activity (pain fibre), it inactivates the inhibitory neurons, so that the pain signals can be sent to the brain in order of pain perception (gates are open).

\section{CONCLUSION}

This theory is based on cognitive- behavioural approach to pain management. This theory helps to explain how interventions based on auditory, visual and tactile stimulation such as music therapy, distraction, and massage therapy provide pain relief. 


\section{ARTICLES}

\section{REFERENCES}

1. Dickenson, A.H. (2002). Gate control theory of pain stands the test of time. British journal of Anaesthesia. June 1; Vol: 88 (6):755-757. https://doi.org/10.1093/bja/88.6.755

2. Melzack, R., Wall, P.D., Pain mechanisms: A new theory. Science. 1965. Nov 19; Vol: 150(3699): 971-979.

3. Jennifer. E. Helms. Claudia, P. (2008). Physiology and treatment of pain. Clinical journal of American Association of critical care Nurse. Vol: 28(6):38-48.

4. Nathan. P., The Gate control theory of pain - A critical review. Brain.1976. Mar; 99(1):123-158.

5. Mazulo, J.M., The gate control theory of pain. British Medical Journal. 1978. Aug 26; 2 (6137):586-587.

6. Paula, J.S., Ethan, A.L. (2017). Gate control theory springs a leak. Neuron. 93(22).723-724. http://dx.doi.org/10.1016/j.neuro.2017.02.016

7. Besson, J.M. (1999). Gate control theory on the evolution of pain concepts. The neurobiology of pain. Vol.353 (9164). http://doi.org/10.1016/s0140/6736(99)01313-6

8. Viatcheslav, W., Gate control theory and pain management. Neuro science and neurology. 2014. June 23. 